\title{
A NOTE ON CHILOSIA HIAWATHA SHANNON
}

\author{
By Charles W. Johnson \\ Boston Society of Natural History.
}

This species was described in $1922^{1}$ from a single male collected by Dr. Jos. Bequaert at Forest Hills, Mass. On June 4, 1922, Mr. W. S. Brooks took a female at Topsfield, Mass., that I though might be Chilosia haiwatha, but the bare eyes and several minor differences seemed to make the determination doubtful. On June 10, 1926, Mr. F. H. Walker collected a male at Danvers, Mass., but from the description I was still doubtful. In June, 1928, Dr. J. P. Bill took a female at Wayland, Mass. On June 16, 1928, I collected a female at East Gloucester, Mass. On June 14 and 17, 1929, I again visited the same place, near Braces Cove, East Gloucester, and captured twenty-one specimens, including three males. Most of the specimens were taken on the flowers of the tall buttercup (Ranunculus acris). On June 16, 1929, Mr. Nathan Banks took a female at Holliston, Mass.

I now felt sure that these were the males and females of Chilosia hiawatha, notwithstanding the sexual differences and discrepancies in the original description. To make sure, however, I submitted a male to Mr. Charles T. Greene of the U. S. National Museum, pointing out some of the characters not clearly defined in the description, and received the following note based on the type.

"The 'central, longitudinal groove' is in the frontal triangle (not the ocellar triangle); the halter is pale luteous with a brownish infuscation at the base of the stem

1A Revision of the Chilosini. By Raymond C. Shannon Insec. Inecit., vol. 10, pp. 47-145. 
and a brownish spot on the knob. Abdominal pile long and yellow, under side of all tarsi with yellowish pubescence; joints 2, 3, and 4 of front tarsi are slightly more brownish in the type than in your specimen. Your specimen is slightly smaller than the type, but otherwise it is identical."

The female has the eyes bare; the third joint of the antennae is often more brownish than in the male; the front, about one-fifth the total width of the head, is black, shining, with three slight grooves; lower parts of the orbits whitish pubescence. The 2nd, 3rd, and 4th joints of the front tarsi are often darker than in the male the latter being often decidedly yellow. The pile on the abdomen short and oppressed. Wings more yellowish at the base and the knobs of the halters entirely yellow. The species vary from 9 to $10 \mathrm{~mm}$.

Becker restricted the genus Chilosia to those species having hairy eyes and antennal pits. Those with bare eyes and with the antennal pits confluent were placed in the genus Cartosyrphus Bigot. Shannon says: "Unfortunately the type species of Chilosia, flavipes, has the eyes sometimes bare in the female, but the writer believes that this species will be found to have the anntennal pits separated which would put the genus Chilosia on a better basis."

If the narrow oblique impressed lines extending from the base of the antennae to the orbits, can be called antennal pits, then this species could be referred to Chilosia, otherwise it would be difficult to separate the female from species of Cartosyrphus which have similar oblique impressed lines. The genus Cartosyrphus seems to stand on very weak characters. 

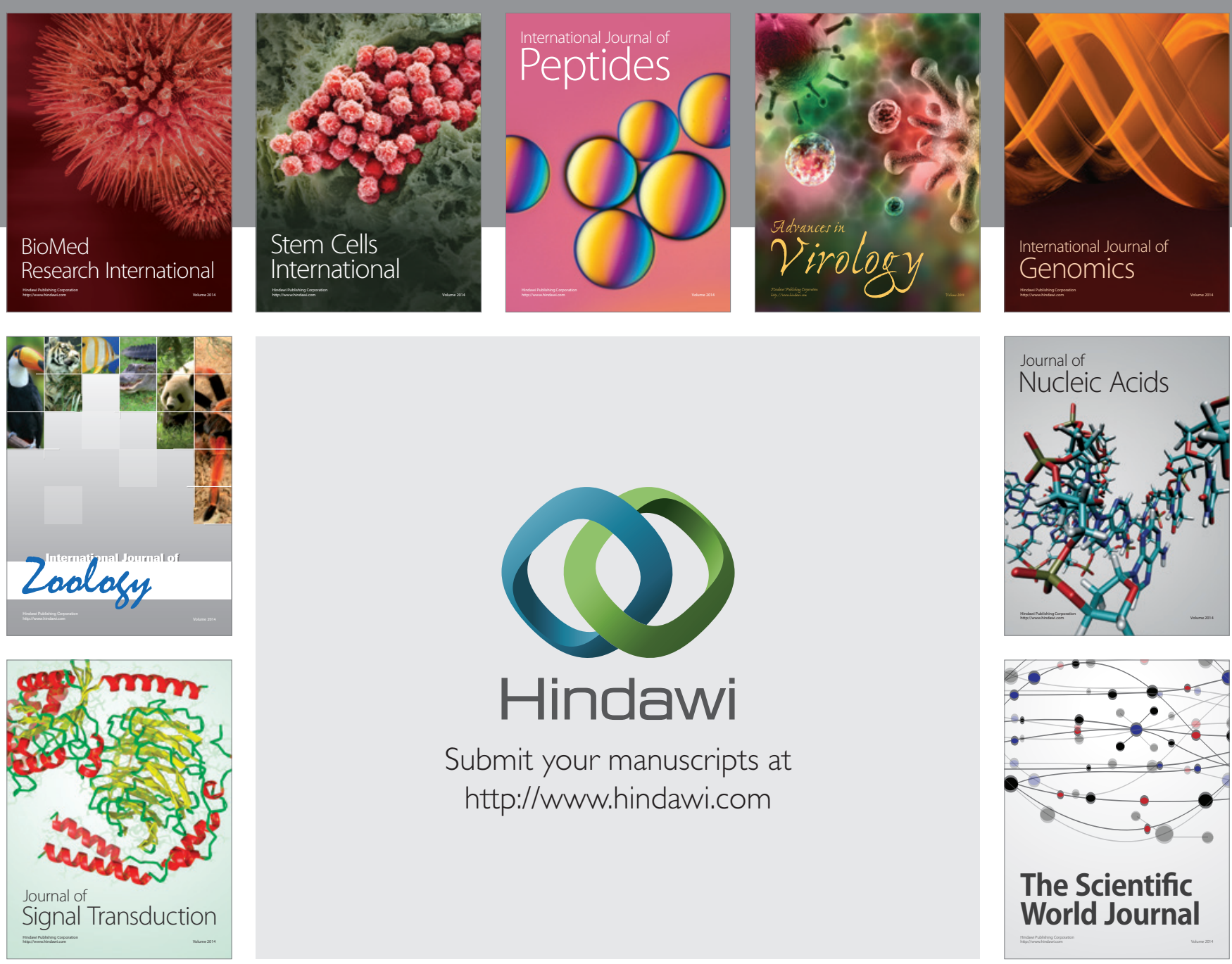

Submit your manuscripts at

http://www.hindawi.com
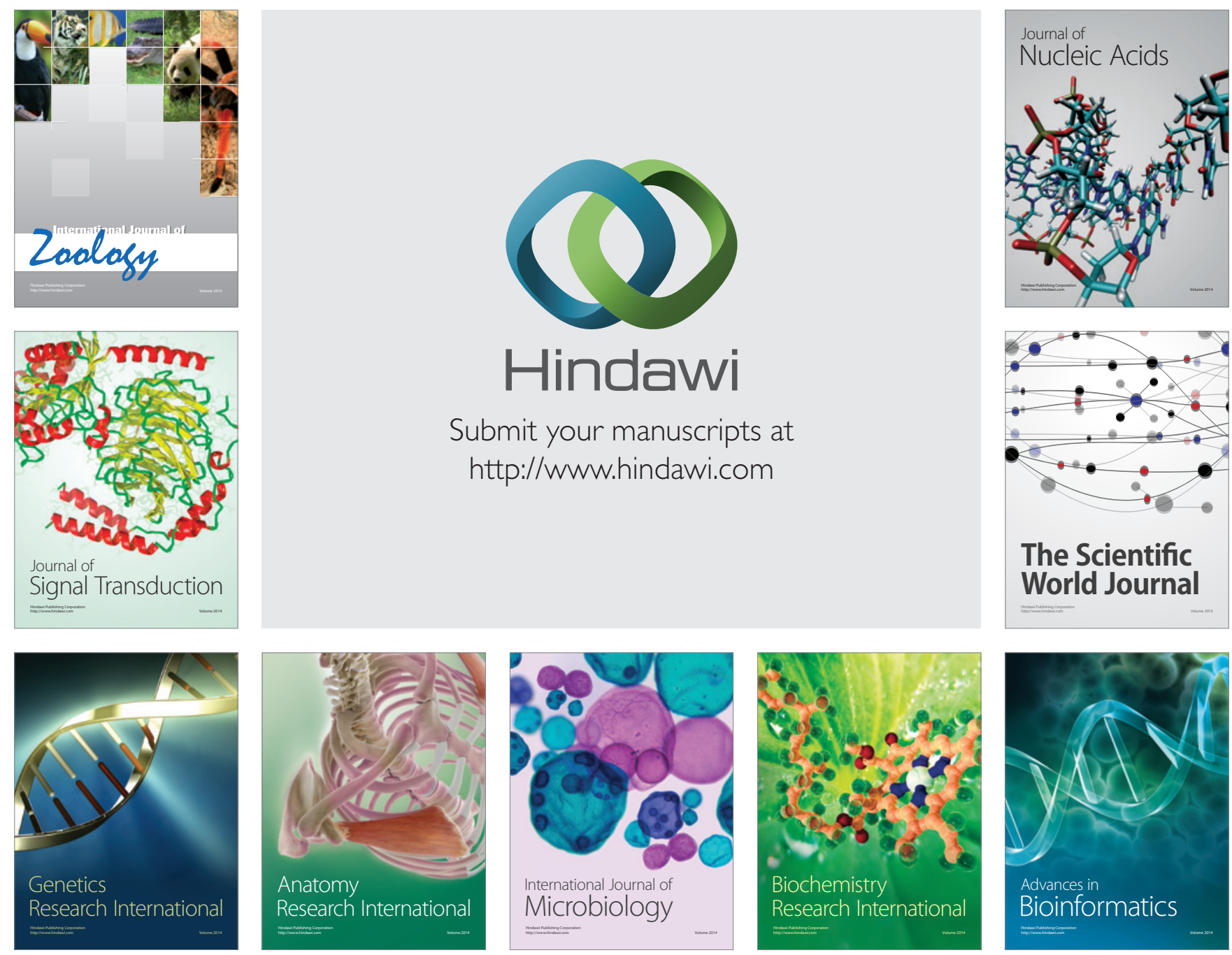

The Scientific World Journal
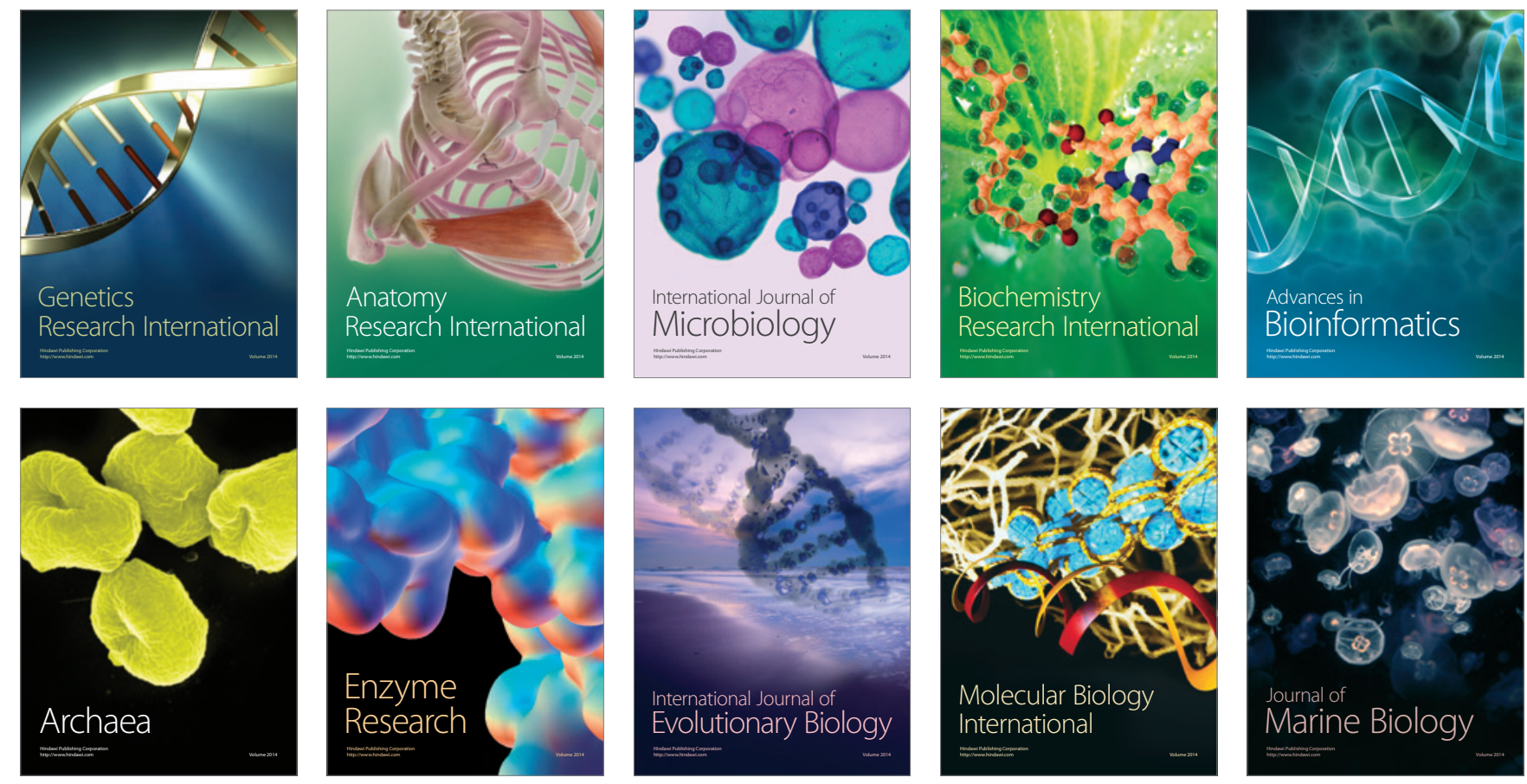